\title{
Effect of Capital Constraint in a Dual-Channel Supply Chain
}

\author{
Lang Xu $\mathbb{D}^{1,2}$ Jia Shi $\mathbb{D}^{1}{ }^{1}$ and Jihong Chen ${ }^{1}$ \\ ${ }^{1}$ College of Transport and Communications, Shanghai Maritime University, Shanghai, China \\ ${ }^{2}$ School of Administrative Studies, York University, Toronto, Canada \\ Correspondence should be addressed to Lang Xu; jerry_langxu@yeah.net
}

Received 3 August 2020; Revised 17 August 2020; Accepted 25 September 2020; Published 4 November 2020

Academic Editor: Thiago Christiano Silva

Copyright ( $\odot 2020$ Lang Xu et al. This is an open access article distributed under the Creative Commons Attribution License, which permits unrestricted use, distribution, and reproduction in any medium, provided the original work is properly cited.

Capital constraint is a significant factor that mainly restricts the development of small- and medium-sized enterprises. This paper explores the channel strategy and pricing decision in a dual-channel supply chain, which consists of one supplier and one retailer. Adequate and inadequate capital constraints for the supplier are distinguished by determining whether open the retail channel to sell. The observations offer managerial insights into supply chain member. First, the results indicate that the capital constraint is a key factor affecting channel strategies and pricing decisions. With the increased value of capital constraint, the wholesale price of offline channel and the selling price of online channel firstly decrease and then remain constant. Second, the results demonstrate that, with capital constraint, the supplier pays more attention to consumers' brand loyalty if it chooses to open the online channel only. Additionally, the price-sensitivity parameter has no effect on the strategy of opening only the offline channel. Moreover, when the channel competition is too intense, the supplier will choose to only open the online channel strategy and increase the online selling price if the capital is insufficient.

\section{Introduction}

The foundation for daily operation activities for an enterprise is working capital. It can be said that capital is the prerequisite and decisive factor for enterprise to carry out production and operation activities $[1,2]$. However, the small- and medium-sized enterprises account for over half of the world's gross domestic product and employment in major economy, yet there is a widespread shortage of capital liquidity. For example, during the 2008 global financial crisis, a large number of companies ran into financial difficulties as production expanded and raw material prices and labor costs rose. In addition, the capital shortage will not only restrict the production and operation of enterprises but also bring the inventory and shortage risks to the upstream and downstream, thus affecting the stable development of the entire supply chain. At the same time, with the development of e-commerce and Internet technology, many manufacturers win customers and increase market share by opening online channels [3,4]. In addition, opening an online channel increases the operating cost, which causes capital constraint to become a significant factor affecting the opening of online channel. With the rapid development of economic globalization and consumer demand, as a new sales channel, the demand of online channel is rapidly increasing, and opening the online channel needs to burden the certain risks, so the degree of risk aversion of firms has an important impact on channel selection strategy and pricing decisions [5].

Under the background, we investigate the following questions: Compared to the case without capital constraint, how does the supplier adjust the operational strategies and pricing decisions and maximize the profit? How does capital constraint affect the members' decision-making in a dualchannel supply chain? Is there a threshold of capital constraint that can achieve a supply chain, the condition on which sale channel to be opened?

To address these questions, we analyze the channel choice in a one-supplier-one-retailer supply chain, where the supplier is capital-constrained. The optimal pricing strategies are discussed under different scenarios and the profits of supplier and retailer are compared. Further, we investigate the condition for opening dual-channel supply chain and explore the effects of capital constraint. The main 
contributions of our research are summarized in the following respects. First, it describes how capital constraint affects channel strategies and pricing decisions in a multidual supply chain. Second, it identifies the relationships among the pricing decisions, consumer behavior, and pricesensitivity parameter. Third, it compares the optimal decisions and profits of members under the different scenarios of capital constraint.

The remainder of the paper is organized as follows. We review the related literature in Section 2. The problem description and model assumption are introduced in Section 3. Section 4 investigates and compares the optimal decision under different capital constraints. We conduct the numerical analysis in Section 5. Finally, the conclusion is given in Section 6.

\section{Literature Review}

In this section, we give an overview of closely relevant literature on channel selection strategy, consumer behavior across channel, and capital constraints in operational management.

2.1. Channel Selection Strategy in Supply Chain. Channel selection strategy is a hot issue in marketing research and operational research. This work in this stream is mainly on sale channel selection [6-8], recycling channel selection [9-12], distribution channel selection [12-14], and return channel selection [15-17]. Furthermore, several scholars investigated the conditions for the case where opening an additional online channel is optimal [18-22] and found that the channel selection was dependent on the substitutable coefficient between online and offline channels. In addition, some interesting researches explore the multidecision optimization problem under dual-channel structure, such as low-carbon supply chain [23-26] and remanufacturing supply chain [26-28]. Moreover, Zhou et al. [29] analyzed the impact of asymmetric information in the presence of channel choice and pricing strategy and found that the downstream weakens the service provider's advantage via channel selection. Under the multichannel competition, Wang et al. [30] proposed the model of channel choice and pricing decisions and found that the difference among multiple channels' operational costs was a critical factor in the downstream's selection. Considering the demand uncertainties in online channel and offline channel, Modak and Kelle [31] demonstrated the pricing decision and ordering decision in a delivery-time supply chain to examine the impact of consumer channel loyalty on members' profits. Most of above literature considered a supply chain in which the manufacturer opened an online channel and found primarily the effect of channel difference on channel selection strategy. However, none of these scholars involved the situation of retailer's encroachment in online channel. This paper combines the ignored issue to investigate the conditions and boundaries on three scenarios of channels, i.e., online channel, offline channel, and dual channel.
2.2. Consumer Behavior across Purchasing Selection. Obviously, the consumers are influenced by different types of preferences including price and quality. For monitoring the environmental performance of green product in consumers' awareness, some scholars found more environmental factors in choosing the product, such as low-carbon product [32, 33] and remanufactured product [34-37]. Furthermore, some scholars have made an analysis from the empirical perspective; these include Aguilar and Vlosky [38] and $\mathrm{Ma}$ et al. [39]. In particular, some scholars have also studied the influence of consumer preference on the performances of dual channel and multichannel. Liu et al. [40] discussed the different dynamic network structure of supply chain members via a two-stage game model to analyze the effect of consumer environmental awareness on the equilibriums. The above studies showed that the increase of consumer environmental awareness is beneficial to environment-friendly manufacturer and retailer. Ji et al. [41] considered cap-and-trade regulation to study the condition whether opening a direct channel is affected by low-carbon preference and found that when the degree of consumer's preference is in a certain interval, dual channel is advantageous to the manufacturer. Additionally, some researches focus on the effects of low-carbon preference on channel selection. Khouja et al. [42] introduced consumer behavior into the channel strategies of different structures and observed that the combination of channel option and consumer behavior is the important factor to affect channel selection.

Accordingly, consumers' selection of purchase channel is mainly depending on their preference. In the existing research, most scholars focused on only one preference. Although many studied the multifactor analysis in consumer behavior, they subdivided the market based on consumers' preference and concentrated on a special market to discuss their strategies. Actually, we attempt to subdivide the different brand loyalty between online channel and offline channel. Hence, in such situation, considering consumer behavior in channel selection is necessary for operational management.

\subsection{Capital Constraint in Operational Management.} There has been limited research on the influences of capital constraint in operational management [43] (https://www. sciencedirect.com/science/article/pii/S0925527319300994) [44-46]. Ding et al. [43] considered the interaction and influence of capital constraint on decision from the perspective of risk management. Xu and Birge [46] analyzed the single cycle newsboy problem and explained how capital constraints and capital structure affect the inventory decisions of enterprises. On this basis, $\mathrm{Xu}$ and Birge [47] established a model to study the optimal operation decision under the conditions of capital constraint and management incentive. Ma et al. [45] analyzed the optimal inventory strategy when retailers face the risk attitude of capital shortage and loss aversion. Dada and $\mathrm{Hu}$ [44] studied the impact of the constraint of the enterprise's own capital on its procurement decision under the condition of 
uncertain demand. In terms of supply chain coordination, Jin et al. [48] established a supply chain model consisting of a supplier, a capital-constrained retailer, and consumers and analyzed contract type under sales promotion in supply chain coordination. Feng et al. [49] assumed that the members are constrained by budgets and proposed a gain-sharing contract to coordinate supply chains. Wang and Zhang [50] studied a remanufacturer's production strategy with capital constraints and differentiated demand in a closed-loop supply chain.

The literature mainly analyzes channel selection strategy in supply chain, consumer behavior across purchasing selection, and capital constraint in operational management, which can be summarized in Table 1 . However, most of the above studies consider the decision-making behavior of retailers under capital constraint and do not consider the decision-making of suppliers under capital constraint. The transformation to "specialized and innovative" is the direction of the development of small- and medium-sized suppliers, which means that solving financial constraints is crucial to the development of small- and medium-sized suppliers. On this basis, this paper proposes the impact of capital constraint on pricing strategy of suppliers' online and offline channels under different scenarios and compares the equilibrium under different scenarios.

\section{Problem Description and Assumption}

In this paper, we explore the channel selection and pricing decision in a dual-channel supply chain, where the supplier determines the wholesale price to retailer in the offline channel and selling price in the online channel under the capital constraint $K$. Further, the retailer investigates the retail price. Owing to the price difference between online and offline channels, we consider that the consumers are of two types: physical loyalty and brand loyalty. The consumers with physical loyalty buy products via retailer, whereas those with brand loyalty buy products through supplier and retailer. In other words, the former will use offline channels to buy products, while the latter will use online channels. Moreover, similar to Cai et al. [54] and Xu et al. [55], we assume that the proportions of brand loyalty and physical loyalty are $\theta$ and $1-\theta$. Further, the potential market demands and selling prices of online channel and offline channel are, respectively, $d_{i}$ and $p_{i}$, where $i=s$ or $r$. In addition, we assume that $c_{s}$ and $c_{r}$ are the operational costs of the two channels. To model the profit and obtain the equilibrium, we consider the linear demand function [1]. Therefore, before the supplier or the retailer enters the direct channel, we find the online demand $D_{s}^{0}=0$ and the offline demand $D_{r}^{0}=d_{r}\left(1-p_{r}\right)$. After the retailer enters the direct channel but the supplier does not, the online demand is $D_{s}^{0}=$ 0 and the offline demand is $D_{r}^{0}=\left(d_{r}+d_{s}\right)\left(1-p_{r}\right)$. However, if both the supplier and retailer enter, the selling prices of the two channels are inconsistent, and consumers may switch the original channel to the other channels as the channel substitution $\eta$ of price gap affects the consumer's choice. Therefore, the demand functions for online channel and offline channel can be depicted as follows:

$$
\begin{aligned}
& D_{s}=d_{s}\left[\theta\left(1-p_{s}\right)-\eta\left(p_{s}-p_{r}\right)\right], \\
& D_{r}=d_{r}\left(1-p_{r}\right)+d_{s}\left[(1-\theta)\left(1-p_{r}\right)+\eta\left(p_{s}-p_{r}\right)\right] .
\end{aligned}
$$

\section{Model Equilibriums}

In this section, we investigate the channel strategies and pricing decisions for supply chain, in which the supplier's capital is restricted. In order to have more concise results, we denote $\psi=\left(A c_{r}-\eta c_{s} d_{s}\right)^{2}+2 B c_{s}^{2} d_{s}>0$, where $A=d_{r}+(1+$ $\eta-\theta) d_{s}>0$ and $B=(n+\theta) d_{r}+\left(\eta+\theta-\theta^{2}\right) d_{s}>0$.

4.1. Pricing Decision for Retailer. According to the Stackelberg game, we consider that the supplier is the leader and the retailer is the follower. Based on the selling price of online channel and wholesale price of offline channel made by the supplier, the retailer decides the selling price of offline channel to maximize its own profit, so the expression is as follows:

$$
\max \pi_{r}=\left(p_{r}-w\right) D_{r} .
$$

Based on the backward induction, given $p_{s}$ and $w$, the retailer determines the selling price of offline channel to maximize profit. The second derivate with respect to the selling price of offline channel is $\partial^{2} \pi_{r} / \partial p_{r}^{2}=-2 A<0$, which means that the retailer's profit is a jointly concave function in the selling price. Hence, we have the optimal selling price $p_{r}^{*}=\left[d_{r}+d_{s}\left(1-\theta+\eta p_{s}\right)+A w\right] / 2 A$. Therefore, the above means that retailer's response of selling price needs to consider the impact of demand market and pricing strategies, so next we discuss the supplier's equilibrium.

\subsection{Pricing Decisions for Supplier}

4.2.1. Supplier's Capital Is Adequate. Under this case, the supplier's capital being adequate indicates that costs of the supplier operating online channel and offline channel do not exceed the constraint $K$. Considering the demands between the two channels are nonnegative, the optimization problem for supplier if the capital is adequate is the solution to

$$
\begin{aligned}
& \max \pi_{s}=\left(p_{s}-c_{s}\right) D_{s}+\left(w-c_{r}\right) D_{r} \\
& \text { s.t. }\left\{\begin{array}{l}
D_{s} \geq 0, \\
D_{r} \geq 0, \\
c_{s} D_{s}+c_{r} D_{r}<K .
\end{array}\right.
\end{aligned}
$$

Proposition 1. The optimal channel strategy and pricing decisions for supplier with adequate capital constraint are shown in Table 2.

Here, we use A to indicate that the supplier's capital is adequate and $\mathrm{O} / \mathrm{C}$ to indicate the opening/closing of online and offline channels. 
TABLE 1: The gap between existing literature and our research.

\begin{tabular}{lccc}
\hline & Channel selection & Consumer behavior & Capital constraint \\
\hline$[15,18,20,23,28,50,51]$ & $\sqrt{ }$ & $\sqrt{ }$ \\
{$[2,20,24,34,47,48,52]$} & $\sqrt{ }$ & & $\sqrt{ }$ \\
{$[4,14,15,28,49,53]$} & $\sqrt{ }$ & $\sqrt{ }$ & $\sqrt{ }$ \\
{$[1,10,22,30,33,40,41]$} & & $\sqrt{ }$ & $\sqrt{ }$ \\
Our research & $\sqrt{ }$ & & \\
\hline
\end{tabular}

TABLE 2: The optimal strategy and pricing decisions with adequate capital constraint.

\begin{tabular}{lc}
\hline The channel strategy & The pricing decisions \\
\hline A-C-C & $p_{s}=1, w=1$ \\
A-O-C & $p_{s}=\left(1+c_{s}\right) / 2, w=2 A-\left(1-c_{s}\right) \eta d_{s} / 2 A$ \\
A-C-O & $p_{s}=\left(\left[2 \theta+\left(1+c_{r}\right) \eta\right] A+2 B\right) /(2[(\eta+\theta) A+B]), w=\left(1+c_{r}\right) / 2$ \\
A-O-O & $p_{s}=\left(1+c_{s}\right) / 2, w=\left(1+c_{r}\right) / 2$ \\
\hline
\end{tabular}

Proof. Substituting the response of $p_{r}^{*}$ into Formula (3), we obtain the Hessian matrix with respect to the selling price of online channel and wholesale price of offline channel is

$$
H^{s}=\left[\begin{array}{cc}
\frac{\partial^{2} \pi_{s}}{\partial p_{s}^{2}} & \frac{\partial^{2} \pi_{s}}{\partial p_{s} \partial w} \\
\frac{\partial^{2} \pi_{s}}{\partial w \partial p_{s}} & \frac{\partial^{2} \pi_{s}}{\partial w^{2}}
\end{array}\right]=\left[\begin{array}{cc}
-\frac{d_{s}\left(2 B+\eta^{2} d_{s}\right)}{A} & \eta d_{s} \\
\eta d_{s} & -A
\end{array}\right] .
$$

Obviously, it is easy to have $\left|H_{1}^{s}\right|=-d_{s}\left(2 B+\eta^{2} d_{s}\right) / A<0$ and $\left|H_{2}^{s}\right|=2 B d_{s}>0$. Therefore, the Hessian matrix of supplier's profit function is negatively defined. In addition, we introduce Karush-Kuhn-Tucker conditions to characterize the optimality condition and model a Lagrangian function of optimization problem expressed as $L_{s}=\pi_{s}+\lambda_{1}\left[K-\left(c_{s} D_{s}+c_{r} D_{r}\right)\right]+\lambda_{2} D_{s}+\lambda_{3} D_{r}$, where $\lambda_{1}$, $\lambda_{2}$, and $\lambda_{3}$ are the multipliers corresponding to the slack variables [56]. For ensuring that the supplier's capital is adequate, we have $\lambda_{1}=0$. Hence, the channel choice and pricing strategies are discussed as follows:

(i) Case 1: $\lambda_{1}=0, \lambda_{2}>0$, and $\lambda_{3}>0$ mean that the supplier will not open both online channel and offline channel if the capital is adequate (A-C-C Strategy). Equating the first-order conditions to zero and solving the KKT conditions, we have the optimal decisions $p_{s}=1$ and $w=1$. Meanwhile, the solutions satisfy the conditions $c_{s}>1$ and $c_{r}>1$, so $c_{s}>p_{s}$ and $c_{s}>w$, which show that the margin profits of the supplier's online channel and offline channel are negative. Therefore, the supplier will not choose to open dual channels, which will not be discussed too much later because the situation is not common in practice.

(ii) Case 2: $\lambda_{1}=0, \lambda_{2}=0$, and $\lambda_{3}>0$ mean that the supplier will open online channel but not offline channel if the capital is adequate (A-O-C Strategy). Equating the first-order conditions to zero and solving the KKT conditions, we have $p_{s}=\left(1+c_{s}\right) / 2$ and $w=\left[2 A-\left(1-c_{s}\right) \eta d_{s}\right] / 2 A$. (iii) Case 3: $\lambda_{1}=0, \lambda_{2}=0$, and $\lambda_{3}=0$ mean that the supplier will open offline channel but not online channel if the capital is adequate (A-C-O Strategy). Equating the first-order conditions to zero and solving the KKT conditions, we have $p_{s}=$ $\left(\left\{\left[2 \theta+\left(1+c_{r}\right) \eta\right] A+2 B\right\}\right) /(2[(\eta+\theta) A+B])$ and $w=\left(1+c_{r}\right) / 2$.

(iv) Case 4: $\lambda_{1}=0, \lambda_{2}>0$, and $\lambda_{3}>0$ mean that the supplier will open dual channels if the capital is adequate (A-O-O Strategy). Equating the first-order conditions to zero and solving the KKT conditions, we have $p_{s}=\left(1+c_{s}\right) / 2$ and $w=\left(1+c_{r}\right) / 2$.

From Proposition 1, we find that there are four optimal channel strategies when the supplier's capital is adequate. Moreover, although optimal wholesale and selling price are not affected by the capital constraint in Table 1, the supplier's channel strategies also need to consider capital in order to maintain the capital adequate. Specifically, when $K>B\left(1-c_{s}\right) c_{s} d_{s} / 2 A$, the supplier will choose to open online channel but not offline channel owing to high cost of retailing. When the threshold $K>A B c_{r}\left(1-c_{r}\right) /$ $2[(\eta+\theta) A+B]$, the supplier will choose to open the offline channel but not online channel because of high investment of offline channel. Further, when the threshold $K>\left[c_{s} d_{s}\left(A \theta+B c_{s}\right)+A c_{r}\left(A-\eta d_{s}\right)-\psi\right] / 4 A$, the supplier will choose to open dual channels.

4.2.2. Supplier's Capital Is Fully Used. When the supplier's capital is fully used, it means that the channel selection is influnced by the constraint $K$. Similarly, the demands of online channel and offline channel are nonnegative. Therefore, the optimization problem of supplier's profit can be expressed as follows:

$$
\begin{aligned}
& \max \pi_{s}=\left(p_{s}-c_{s}\right) D_{s}+\left(w-c_{r}\right) D_{r} \\
& \text { s.t. }\left\{\begin{array}{l}
D_{s} \geq 0 \\
D_{r} \geq 0 \\
c_{s} D_{s}+c_{r} D_{r}<K .
\end{array}\right.
\end{aligned}
$$


Proposition 2. The optimal channel strategy and pricing decisions when supplier's capital is fully used are shown in Table 3.

Here, we use F to indicate that the supplier's capital is fully used and $\mathrm{O} / \mathrm{C}$ to indicate the opening/closing of online and offline channels.

Proof. From the above, we get the Lagrangian function $L_{s}=\pi_{s}+\lambda_{1}\left[K-\left(c_{s} D_{s}+c_{r} D_{r}\right)\right]+\lambda_{2} D_{s}+\lambda_{3} D_{r}$, where $\lambda_{1}>0$ to ensure that the supplier's capital is fully used. We can calculate the optimal decisions as follows:

(i) Case 1: $\lambda_{1}>0, \lambda_{2}=0$, and $\lambda_{3}>0$ mean that the supplier will open online channel but not offline channel if the capital is fully used (F-O-C Strategy). Equating the first-order conditions to zero and solving the KKT conditions, we have $p_{s}=1-A K / B c_{s} d_{s}$ and $w=1-(\eta K) /\left(B c_{s}\right)$.

(ii) Case 2: $\lambda_{1}>0, \lambda_{2}>0$, and $\lambda_{3}=0$ mean that the supplier will open offline channel but not online channel if the capital is fully used (F-C-O Strategy). Equating the first-order conditions to zero and solving the KKT conditions, we have $p_{s}=1-(\eta K) /\left(c_{r} B\right)$ and $w=1-(K[(\eta+\theta) A+$ $B]) /(A B) c_{r}$.

(iii) Case 3: $\lambda_{1}>0, \lambda_{2}>0$, and $\lambda_{3}=0$ mean that the supplier will produce both the online channel and offline channel if the capital is fully used (F-O-O Strategy). Equating the first-order conditions to zero and solving the KKT conditions, we have $p_{s}=\left\{\psi+c_{s}^{2} d_{s}(\theta A+B)+c_{s} A\left[c_{r}\left(A-\eta d_{s}\right)-4 K\right]\right\} /$ $2 \psi$ and $w=\left\{\psi+c_{s} c_{r} d_{s}(\theta A+B)+c_{r} A\left[c_{r}\left(A-\eta d_{s}\right)\right.\right.$ $-4 K]\} / 2 \Psi$.

Proposition 2 illustrates that three optimal channel strategies exist when the supplier's capital is fully used, and the optimal wholesale of offline channel and selling price of online channel are correlated with the capital constraint at this time. Further, if $K<\left(1-c_{s}\right) c_{s} d_{s} B / 2 A$ or $K<\left(c_{r}-c_{s}\right) c_{s} d_{s} B / 2\left(c_{r} A-\eta c_{s} d_{s}\right)$, the supplier will use all capitals to open online channel but not offline channel.
Similarly, if the threshold $K<\left(1-c_{r}\right) c_{r} A B / 2[(\eta+\theta) A+B]$, the supplier will use all of the capitals to open offline channel but not online channel. Meanwhile, if the threshold satisfies $\left(1-c_{r}\right) c_{r} A B / 2[(\eta+\theta) A+B]<K<\left[c_{s} d_{s} \quad\left(\theta A+c_{s} B\right)+c_{r} A\right.$ $\left.\left(A-\eta d_{s}\right)-\psi\right] / 4 A$, the supplier will use all of the capitals in opening both online channel and offline channel.

4.3. Comparison of Different Strategies under Capital Constraints. This subsection first analyzes the impact of parameters and capital constraint under different channel strategies and then compares the optimal pricing and profits of different channel strategies when the supplier's capital is sufficient and fully utilized.

Proposition 3. The thresholds of $c_{s}$ and $K$ defined seven channel selection regions as shown in Table 4.

Proof

(1) A-O-C Strategy. According to $\lambda_{1}=0, \lambda_{2}=0$, and $\lambda_{3} \geq 0$, we can get $K-\left(c_{s} D_{s}+c_{r} D_{r}\right) \geq 0$, $D_{s}=\left(\left(1-c_{s}\right) d_{s} B\right) / 2 A \geq 0, \quad$ and $\quad\left[c_{r} A-d_{r}-\right.$ $\left.\left(1-\theta+\eta c_{s}\right) d_{s}\right] / A \geq 0$. Combining the three inequalities, we know that $K^{*} \geq\left(\left(1-c_{s}\right) c_{s} d_{s} B\right) / 2 A$ and $c_{s}^{*}<\left[\eta d_{s}-\left(1-c_{r}\right) A\right] / \eta d_{s}$. Similarly, according to the inequality, we can get $\theta^{*} \geq\left[1-c_{r}+\eta\left(c_{s}-c_{r}\right)\right] /\left(\left(1-c_{r}\right)+d_{r} / d_{s}\right) \quad$ and $\eta^{*} \geq\left(1-c_{r}\right)\left[d_{r}+(1-\theta) d_{s}\right] /\left(c_{r}-c_{s}\right) d_{s}$. For the sake of simplicity, we set $\theta_{2}=\left[1-c_{r}+\eta\left(c_{s}-c_{r}\right)\right] /\left(1-c_{r}\right)+d_{r} / d_{s} \quad$ and $\eta_{2}=\left(\left(1-c_{r}\right)\left[d_{r}+(1-\theta) d_{s}\right]\right) /\left(c_{r}-c_{s}\right) d_{s}$.

(2) A-C-O Strategy. According to $\lambda_{1}=0, \lambda_{2} \geq 0$, and $\lambda_{3}=0$, we can get $K-\left(c_{s} D_{s}+c_{r} D_{r}\right) \geq 0$, $D_{r}=\left(\left(1-c_{r}\right) c_{r} A B\right) / 2[(\eta+\theta) A+B] \geq 0$, and $\lambda_{2} \geq 0$. Combining the three inequalities, we know that $K^{*} \geq\left(\left(1-c_{r}\right) c_{r} A B\right) / 2[(\eta+\theta) A+B]$ and $c_{s}^{*}>\left(\eta c_{r}+\right.$ $\theta) A+B /[(\eta+\theta) A+B]$. Similarly, for the sake of simplicity, we can also get the range of values for $\theta$ and $\eta$ as follows:

$$
\begin{aligned}
\theta^{*}<\theta_{1}= & \frac{1}{4\left(1-c_{s}\right) d_{s}}\left\{2\left(1-c_{s}\right) d_{r}+\left[2\left(1-c_{s}\right)+\eta\left(1-c_{r}\right)\right] d_{s}\right. \\
& +\sqrt{\left[2\left(1-c_{s}\right) d_{r}-\left(2+\eta-\eta c_{r}-2 c_{s}\right) d_{s}\right]^{2}-8 \eta\left(1-c_{s}\right) d_{s}\left\{\left(1+c_{r}-2 c_{s}\right) d_{r}+\left[1+(1+\eta) c_{r}-(2+\eta) c_{s}\right]\right\}} \\
\eta^{*}<\eta_{1}= & \frac{1}{2\left(c_{r}-c_{s}\right) d_{s}}-\left\{\left(1+c_{r}-2 c_{s}\right) d_{r}-\left[1+\theta+(1-\theta) c_{r}-2 c_{s}\right] d_{s}\right. \\
& \left.+\sqrt{\left[\left(1+c_{r}-2 c_{s}\right) d_{r}+\left(1+\theta+(1-\theta) c_{r}-2 c_{s}\right) d_{s}\right]^{2}-8 \theta\left(c_{r}-c_{s}\right)\left(1-c_{s}\right) d_{s}\left[d_{r}+(1-\theta) d_{s}\right]}\right\}
\end{aligned}
$$

(3) A-O-O Strategy. According to $\lambda_{1}=0, \lambda_{2}=0$, and $\lambda_{3}=0$, we can get $K-\left(c_{s} D_{s}+c_{r} D_{r}\right) \geq 0$, $D_{s}=\left\{\left(\theta+\eta c_{r}\right) A+B-c_{s}[(\eta+\theta) A+B]\right\} / 4 A \geq 0$, and $D_{r}=\left[\left(1-c_{r}\right) A-\left(1-c_{s}\right) \eta d_{s}\right] / 4 \geq 0$. Combining the three inequalities, we know that $K^{*} \geq\left[c_{s} d_{s}\left(\theta A+c_{s} B\right)+c_{r} A\left(A-\eta d_{s}\right)-\psi\right] / 4 A$ and 
TABLE 3: The optimal channel strategy and pricing decisions when supplier's capital is fully used.

\begin{tabular}{lc}
\hline The channel strategy & The pricing decisions \\
\hline F-O-C & $p_{s}=1-(K A) /\left(c_{s} d_{s} B\right), w=1-(K \eta) /\left(c_{s} B\right)$ \\
F-C-O & $p_{s}=1-(K \eta) /\left(c_{r} B\right), w=1-(K([\eta+\theta] A+B)) /\left(c_{r} A B\right)$ \\
F-O-O & $p_{s}=\left(\psi+c_{s}^{2} d_{s}(\theta A+B)+A c_{s}\left[c_{r}\left(A-\eta d_{s}\right)-4 K\right]\right) /(2 \psi), w=\left(\psi+c_{s} c_{r} d_{s}(\theta A+B)\right)+\left(A c_{r}\left[c_{r}\left(A-\eta d_{s}\right)-4 K\right]\right) / 2 \psi$ \\
\hline
\end{tabular}

$$
\begin{aligned}
& \left(\left[\eta d_{s}-\left(1-c_{r}\right) \quad A\right] / \quad \eta d_{s}\right) \leq c_{s}^{*}< \\
& \left(\left[\left(\eta c_{r}+\theta\right) A+B\right] /[(\eta+\theta) A+B]\right) .
\end{aligned}
$$

(4) F-O-C Strategy. According to $\lambda_{1}=0, \lambda_{2}=0$, and $\lambda_{3}=0$, we can get $\left[\left(1-c_{s}\right) c_{s} d_{s} B-2 A K\right] /\left(c_{s}^{2} d_{s} B\right) \geq 0$, $D_{s}=\left(K / c_{s}\right) \geq 0$ and $\left[\left(c_{r}-c_{s}\right) c_{s} d_{s} B-2 K \quad\left(c_{r} A-\right.\right.$ $\left.\left.\eta c_{s} d_{s}\right)\right] /\left(c_{s}^{2} d_{s} B\right) \geq 0$. Combining the three inequalities, we know that $K_{1}<\left(\left(1-c_{s}\right) c_{s} d_{s} B\right) / 2 A$ and $K_{2}<\left(c_{r}-c_{s}\right) c_{s} d_{s} B / 2\left(c_{r} A-\eta c_{s} d_{s}\right)$. By subtracting these two thresholds, we can get $K^{*}<((1-$ $\left.\left.c_{s}\right) c_{s} d_{s} B\right) / 2 A$ when $c_{s}^{*}<\left[\eta d_{s}-\left(1-c_{r}\right) A\right] / \eta d_{s}$ and $K^{*}<\left(\left(c_{r}-c_{s}\right) c_{s} d_{s} B\right) / 2\left(c_{r} A-\eta c_{s} d_{s}\right)$ when $\left[\eta d_{s}-(1-\right.$ $\left.\left.c_{r}\right) A\right] / \eta d_{s} \leq c_{s}^{*}<\left(\left[\left(\eta c_{r}+\theta\right) A+B\right] /[(\eta+\theta) A+B]\right)$.

(5) F-C-O Strategy. According to $\lambda_{1}=0, \lambda_{2}=0$, and $\lambda_{3}=0$, we can get the following three expressions about supplier's capital constraint $\left\{\left(1-c_{r}\right) c_{r} A B-\right.$ $2 K[(\eta+\theta) A+B]\} /\left(c_{r}^{2} A B\right) \geq 0, \quad\left\{2 K\left[\left(c_{r}-c_{s}\right) \eta A-c_{s}\right.\right.$ $\left.(\theta A+B)]-c_{r} \quad\left(c_{r}-c_{s}\right) A B\right\} / \quad\left(c_{r}^{2} A B\right) \geq 0, \quad$ and $D_{r}=\left(K / c_{r}\right) \geq 0$. Combining the above inequalities, we obtain $\left(c_{r}\left(c_{r}-c_{s}\right) A B\right) / 2\left[\left(c_{r}-c_{s}\right) \eta A-c_{s}(\theta A+\right.$ $B)]<K<\left(\left(1-c_{r}\right) c_{r} A B\right) / 2[(\eta+\theta) A+B]$. Meanwhile, the conditions $\left(1-c_{r}\right) c_{r} A B /(2[(\eta+\theta) A+$ $B])>c_{r}\left(c_{r}-c_{s}\right) A B / 2 \quad\left[\left(c_{r}-c_{s}\right) \eta A-c_{s}(\theta A+B)\right]$ if $c_{s}>\left[\left(\eta c_{r}+\theta\right) A+B\right] /[(\eta+\theta) A+B]$ and $\left(c_{r}\left(c_{r}-\right.\right.$ $\left.\left.c_{s}\right) A B\right) / 2\left[\left(c_{r}-c_{s}\right) \eta A-c_{s}(\theta A+B)\right]>0$ if $c_{s}<A^{\eta c_{r}} /$ $[(\eta+\theta) A+B]$ must be satisfied; therefore, $K^{*}<\left(\left(1-c_{r}\right) c_{r} A B\right) / 2[(\eta+\theta) A+B]$ and $c_{s}^{*}>\left[\left(\eta c_{r}+\right.\right.$ $\theta) A+B] /[(\eta+\theta) A+B]$.

(6) F-O-O Strategy. According to $\lambda_{1}=0, \lambda_{2}=0$, and $\lambda_{3}=0$, we can obtain the following three inequalities: $\left\{\left[c_{s} d_{s}\left(\theta A+c_{s} B\right)+c_{r} A\left(A-\eta d_{s}\right)-\psi\right]-4 A K\right\} / \Psi \geq 0$, the demand of online channel $D_{s}=\left\{c_{r}\left(c_{r}-c_{s}\right)\right.$ $\left.A B-2 K \eta c_{r} A+2 c_{s} K \quad[(\eta+\theta) A+B]\right\} / 2 \Psi \geq 0$, and the demand of offline channel $D_{r}=\left\{2 K\left(c_{r} A\right.\right.$ $\left.\left.-\eta c_{s} d_{s}\right)-\left(c_{r}-c_{s}\right) c_{s} d_{s} B\right\} / 2 \Psi \geq 0$. Combining the three inequalities, we can calculate the results that $K_{1}<\left[c_{s} d_{s}\left(\theta A+c_{s} B\right)+c_{r} A\left(A-\eta d_{s}\right)-\psi\right] / 4 A$ and $K_{2}<\left(c_{r}\left(c_{r}-c_{s}\right) A B\right) / 2\left\{\eta c_{r} A-c_{s}[(\eta+\theta) A+B]\right\} \quad$ if $c_{s}>\left(\left[\eta d_{s}-\left(1-c_{r}\right) A\right] / \eta d_{s}\right)$ and $K_{3} \geq\left(\left(c_{r}-c_{s}\right)\right.$ $\left.c_{s} d_{s} B\right) / 2\left(c_{r} A-\eta c_{s} d_{s}\right)$. By subtracting the two thresholds of $K_{1}$ and $K_{2}$, we can get $K_{1}-K_{2}<0$; thus $K_{1}<K_{2}$ and $K^{*}<\left[c_{s} d_{s}\left(\theta A+c_{s} B\right)+c_{r} A(A-\right.$ $\left.\left.\eta d_{s}\right)-\psi\right] / 4 A$. In addition, in order to ensure the thresholds $\quad\left(\left[c_{s} d_{s}\left(\theta A+c_{s} B\right)+c_{r} A\left(A-\eta d_{s}\right)-\psi\right] /\right.$ $4 A) \geq\left(\left(c_{r}-c_{s}\right) c_{s} d_{s} B\right) / 2\left(c_{r} A-\eta c_{s} d_{s}\right)$, the following condition must be satisfied: $\left\{\left[\left(\eta c_{r}+\theta\right) A+B\right]-[(\eta+\right.$ $\left.\theta) A+B] c_{s}\right\} / 4 A\left(c_{r} A-\eta c_{s} d_{s}\right) \geq 0$. Therefore, we can obtain $\left(\left(c_{r}-c_{s}\right) c_{s} d_{s} B\right) / 2\left(c_{r} A-\eta c_{s} d_{s}\right) \leq K^{*}<\quad\left[c_{s} d_{s}\right.$ $\left.\left(\theta A+c_{s} B\right)+c_{r} A\left(A-\eta d_{s}\right)-\psi\right] / 4 A$ and $\left(\left[\eta d_{s}-(1-\right.\right.$ $\left.\left.\left.c_{r}\right) A\right] / \eta d_{s}\right) \leq c_{s}^{*}<\left(\left[\left(\eta c_{r}+\theta\right) A+B\right] /[(\eta+\theta) A+B]\right)$.

Based on the results in Table 3, we derive the following corollaries for management reference.
Corollary 1. The channel decisions are significantly affected by the cost of online channel $c_{s}$ and the capital constraint $K$ and the thresholds of them define seven channel decision regions.

Proof. The corollary shows that the supplier has seven channel strategies to choose from, as well as which ones need to consider capital constraint, consumers' brand loyalty, price-sensitivity coefficient, and production costs. In addition, the above parameters can also have an influence on supplier's judgment as to whether its capital is sufficient.

Corollary 2. For any given $c_{s}$, the supplier will be more inclined to use all capitals as $K$ decreases.

Proof. It is easy to see from Table 3 that, regardless of the value range of $c_{s}$, the $K$ result is sufficient for the supplier when it is greater than the threshold, and the supplier will use the capital completely if the capital constraint $K$ is less than the threshold. As $K$ decreases, capital will be more likely to be fully utilized, and Corollary 2 is proven. Therefore, the supplier needs to pay special attention to the threshold of capital in the actual operations. Once they are lower than this threshold, the supplier needs to make full use of capitals to maximize their effectiveness.

Corollary 3. The maximum value of $K$ when the supplier chooses to use all capitals decreases as $c_{s}$ increases.

Proof. For conveniences, we first define the equations $K_{1}=\left(\left(1-c_{s}\right) c_{s} d_{s} B\right) / 2 A, \quad K_{2}=\left[c_{s} d_{s}\left(\theta A+c_{s} B\right)+c_{r} A(A\right.$ $\left.\left.-\eta d_{s}\right)-\psi\right] / 4 A$, and $K_{3}=\left(1-c_{r}\right) c_{r} A B / 2[(\eta+\theta) A+B]$. Comparing the threshold of $K$, we find $K_{1}-K_{2}=\left(A-\eta d_{s}+\right.$ $\left.A c_{r}+\eta c_{s} d_{s}\right)\left(A c_{r}+\eta c_{s} d_{s}\right) / 4 A>0$ and $K_{2}-K_{3}=[(B+$ $\left.\left.\theta A c_{s}\right)+A \eta\left(c_{r}-c_{s}\right)\right]\left[(B+\theta A)\left(1-c_{s}\right)+A \eta\left(c_{r}-c_{s}\right)\right] d_{s} / 4 A$ $[(\eta+\theta) A+B]>0$; thus, it is easily derived that $K_{1}>K_{2}>K_{3}$. From Table 3, we can see that when $K$ result is less than the threshold, the supplier will choose to use all capitals. Moreover, since the threshold of $K$ takes $K_{1}, K_{2}$, and $K_{3}$ in turn as $c_{s}$ increases, Corollary 3 is proven. This shows that as cost of online channel increases, the threshold of capital that supplier needs to open channels is lower. Therefore, the supplier should carefully investigate changes in market demands to minimize the cost of investment when selecting a channel strategy.

Furthermore, based on the equilibrium results in Table 1 and Table 2, we can obtain additional propositions as follows.

Proposition 4. Whether the supplier's capital is adequate or fully used, (i) the selling price of offline channel is always higher than that of online channel under the dual channel 


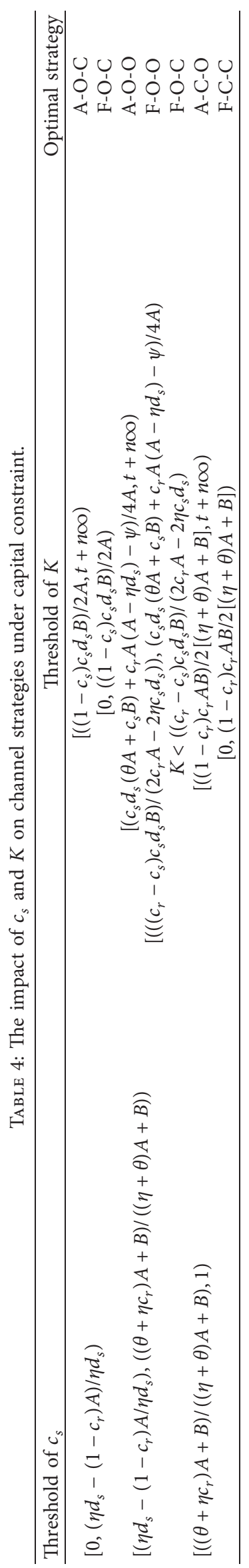


strategy; (ii) if other conditions remain the same, the selling price of opening an online channel is always lower than that of closing online channel, and the opposite is true for an offline channel.

Proof. The above results can be easily obtained by making a difference. Conclusion (i) can be explained by the fact that the offline channel requires other extended services such as physical stores and manual services, which makes the channel costs more expensive, so the corresponding selling price is higher to maintain the profit of the supplier. Conclusion (ii) indicates that suppliers should reduce selling price to attract consumers when they choose to open online channel, but the retail price of retailer in the physical store is higher, which is also due to the large initial costs of opening the store.

Proposition 5. For any $c_{s}$ and $K$ values, the profit of supplier with adequate capitals is always higher than that when capital is fully used under the same channel strategy, namely, O-O strategy, $\mathrm{O}-\mathrm{C}$ strategy, and $\mathrm{C}-\mathrm{O}$ strategy.

Proof. When the supplier chooses to open online channel but not offline channel, the total profits of the supplier are reduced when the capital is sufficient and the capital is fully utilized; then, we easily have $\pi_{m}^{A}-\pi_{m}^{F}=[2 A K+$ $\left.\left(1-c_{s}\right) c_{s} d_{s} B\right]^{2} /\left(4 c_{s}^{2} d_{s} A B\right) \geq 0$; thus, $\pi_{m}^{A}-\pi_{m}^{F}$ is obtained. Similarly, when the supplier chooses to open offline channel but not online channel, the difference of supplier's profits under different capital constraint can be calculated as $\pi_{m}^{A}-$ $\pi_{m}^{F}=\left\{2 K[(\eta+\theta) A+B]+\left(1-c_{r}\right) c_{r} A B\right\}^{2} / 4 c_{r}^{2} A B[(\eta+\theta) A+$ $B] \geq 0$, and if the supplier chooses to open dual channels, the difference of profits is $\pi_{m}^{A}-\pi_{m}^{F} \geq 0$, seen in the numerical analysis because the formula is too complicated; thus, the profit of supplier with adequate capitals is always higher than that when capital is fully used under the same choice. This indicates that no matter which channel strategy the supplier chooses, the greater the capital investment, the greater the profit, so it is advisable for the supplier to keep its available capital sufficient during the course of its operations.

\section{Numerical Analysis}

In this section, we use a numerical example to analyze the threshold of capital constraint on the supplier's channel strategy first and then discuss the impacts of capital constraint, consumers' brand loyalty, and price-sensitivity parameter on optimal prices and profits in detail. Considering the coefficient values used in the existing literature $[4,20$, 57], the parameters of this paper are set as follows: $d_{r}=10$, $d_{s}=50, c_{r}=0.55, c_{s}=0.15, \theta=0.8, \eta=0.5$, and $K=5$.

5.1. Impact of Parameters on Channel Strategies. The impact of consumers' brand loyalty and price-sensitivity parameter on the threshold of capital constraint is described in Table 5. From the previous theoretical analysis, the price-sensitivity parameter and consumers' brand loyalty correspond to three strategies in the different intervals. Therefore, in order to analyze the impact more specifically, we consider that the price-sensitivity coefficient is in three different intervals.

Based on the above, we observe that, with the increasing consumers' brand loyalty, the threshold of capital constraint for the supplier to only open offline channel decreases, while it increases if only opening online channel. This shows that, regardless of the adequacy of capital, as consumers' brand loyalty increases, the capital expenditure should be reduced in the offline channel strategy, while the large-scale investment in online channel strategy should be implemented to obtain higher profit. Moreover, the threshold of capital to open dual channels keeps decreasing as consumers' brand loyalty increases when the capital is adequate, and the opposite is if the capital is fully used. This highlights the importance of adequate capitals for supplier, since, with the increase in consumers' brand loyalty, the decline in the threshold of capital constraint for opening dual channels when the capital is sufficient means less difficulty.

Moreover, with increasing the price sensitivity, the threshold of capital constraint to open only online channel or offline channel will increase. Therefore, the supplier needs to pay more attention to consumers' price sensitivity and replenish capitals in a timely manner when considering opening the corresponding channel. Similar to consumers' brand loyalty, under the dual-channel strategy, as consumer price sensitivity increases, the supplier will invest less and less if it keeps sufficient capital, while if capital is used fully, the investment will increase. Further, the threshold of capital constraint required to open dual channels if capital is adequate is always higher than that when capital is fully utilized. This means that the strategy of full using capitals by the supplier will make it easier to open dual channels.

\subsection{Impact of Supplier's Capital on Decisions and Profits.} Figure 1 describes the impact of supplier's capital on optimal decisions and profits under different channel strategies.

From these four figures, we observe that the optimal decisions and profits change first and then remain constant as capital increases. This means that the supplier's capital will affect its decisions and profits if it is fully used, while it will not affect these results when the capital is adequate. Regardless of the value of $\theta$, the supplier tends to use full capital as the constraint decreases. Hence, the supplier should adjust the decision according to the market in real time when the capital is unstable initially and keep the price constant after the capitals are adequate in the later stage. Specifically, when the supplier moves from offline channel to dualchannel strategy, all participants will attract consumers through reducing prices, and the supplier's effort is significantly greater from Figure 1(b). If the supplier's channel strategy is changed from dual channels to single channel, the price of the corresponding channel should be increased, which is caused by shortening the channel source. Moreover, we can realize that the retail price is higher than the online price when the dual channels are opened, owing to the fact that the physical store will generate costs such as rental and service, which confirms Proposition 4. In addition, regardless of whether the capitals are sufficient, only opening 
TABLE 5: The impact of $\theta$ and $\eta$ on $K$ under different channel strategies.

\begin{tabular}{|c|c|c|c|c|c|c|c|c|c|}
\hline \multirow{2}{*}{$\theta$} & \multirow{2}{*}{$\eta \in\left[0, \eta_{1}\right]$} & \multicolumn{2}{|c|}{ Threshold of $K$} & \multirow{2}{*}{$\eta \in\left[\eta_{1}, \eta_{2}\right]$} & \multicolumn{2}{|c|}{ Threshold of $K$} & \multirow{2}{*}{$\eta \in\left[\eta_{2,1}\right]$} & \multicolumn{2}{|c|}{ Threshold of $K$} \\
\hline & & A & $\mathrm{F}$ & & A & $\mathrm{F}$ & & A & $\mathrm{F}$ \\
\hline \multirow{3}{*}{0.1} & 0.00 & 3.40 & 3.40 & 0.20 & 3.80 & 3.80 & 0.50 & 4.21 & 4.21 \\
\hline & 0.05 & 3.53 & 3.53 & 0.30 & 3.95 & 3.95 & 0.60 & 4.32 & 4.32 \\
\hline & 0.10 & 3.63 & 3.63 & 0.40 & 4.09 & 4.09 & 0.70 & 4.43 & 4.43 \\
\hline \multirow{3}{*}{0.3} & 0.00 & 2.78 & 2.78 & 0.20 & 3.27 & 3.27 & 0.50 & 3.79 & 3.79 \\
\hline & 0.05 & 2.93 & 2.93 & 0.30 & 3.47 & 3.47 & 0.60 & 3.93 & 3.93 \\
\hline & 0.10 & 3.05 & 3.05 & 0.40 & 3.63 & 3.63 & 0.70 & 4.05 & 4.05 \\
\hline \multirow{3}{*}{0.5} & 0.00 & 3.76 & 1.36 & 0.20 & 3.61 & 1.90 & 0.50 & 3.22 & 2.44 \\
\hline & 0.05 & 3.73 & 1.52 & 0.30 & 3.49 & 2.11 & 0.60 & 3.07 & 2.57 \\
\hline & 0.10 & 3.70 & 1.66 & 0.40 & 3.37 & 2.28 & 0.70 & 2.92 & 2.68 \\
\hline \multirow{3}{*}{0.7} & 0.00 & 3.78 & 1.91 & 0.20 & 3.60 & 2.49 & 0.50 & 3.18 & 3.00 \\
\hline & 0.05 & 3.75 & 2.08 & 0.30 & 3.48 & 2.70 & 0.60 & 3.10 & 3.10 \\
\hline & 0.10 & 3.71 & 2.24 & 0.40 & 3.33 & 2.86 & 0.70 & 3.16 & 3.16 \\
\hline \multirow{3}{*}{0.9} & 0.00 & 3.80 & 2.45 & 0.20 & 3.59 & 3.12 & 0.50 & 3.47 & 3.47 \\
\hline & 0.05 & 3.77 & 2.68 & 0.30 & 3.44 & 3.32 & 0.60 & 3.51 & 3.51 \\
\hline & 0.10 & 3.72 & 2.85 & 0.40 & 3.42 & 3.42 & 0.70 & 3.54 & 3.54 \\
\hline
\end{tabular}
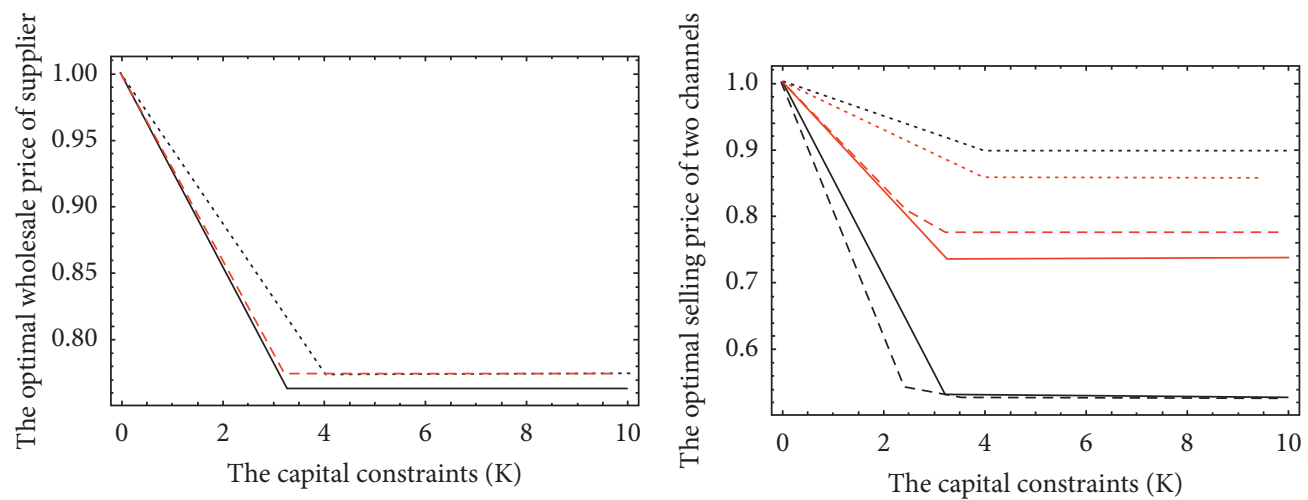

$$
\begin{aligned}
& \cdots \cdots w^{\theta}=0.2 \\
& --w^{\theta=0.5} \\
& -w^{\theta=0.8}
\end{aligned}
$$

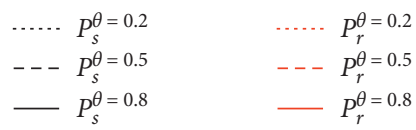

(b)

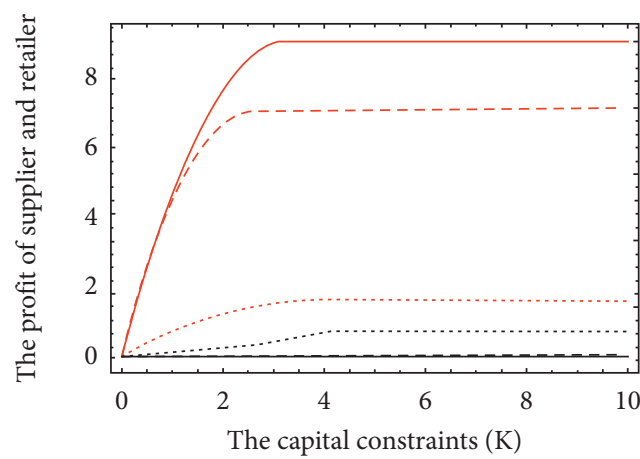

$$
\begin{array}{ll}
\cdots \cdots & \pi_{r}^{\theta=0.2} \\
--\pi_{r}^{\theta=0.5} & ---\pi_{s}^{\theta=0.2} \\
-\pi_{r}^{\theta=0.8} & -\pi_{s}^{\theta=0.5}
\end{array}
$$

(c)

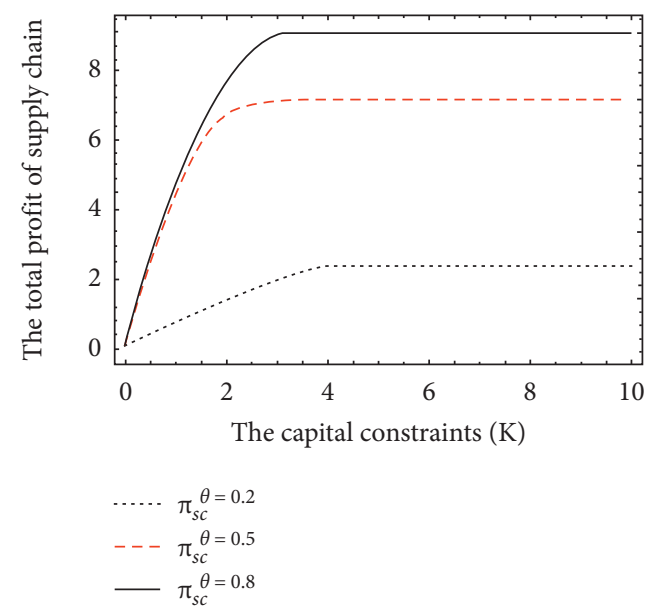

(d)

Figure 1: The impact of supplier's capital on decisions and profits. (a) The impact of $K$ on channel prices. (b) The impact of $K$ on channel quantities. (c) The impact of $K$ on channel profits. (d) The impact of $K$ on supplier's profit. 


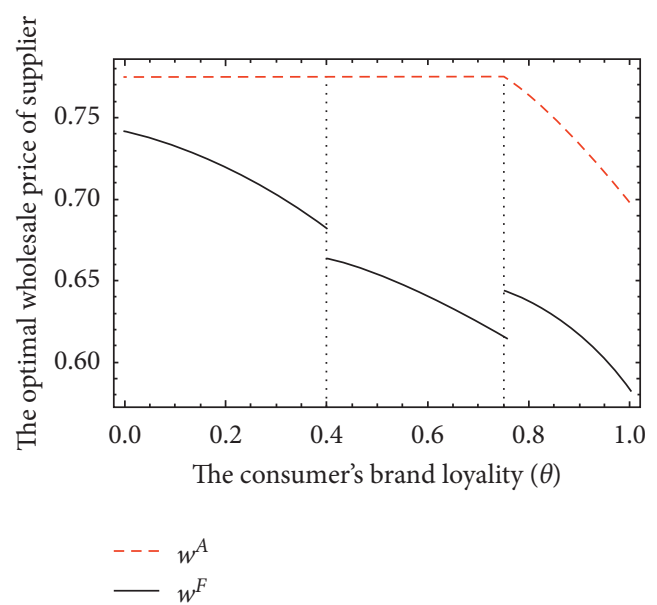

(a)

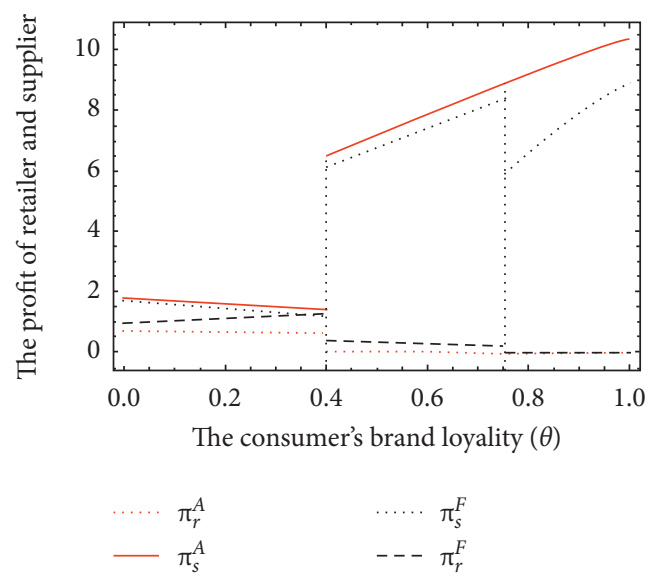

(c)

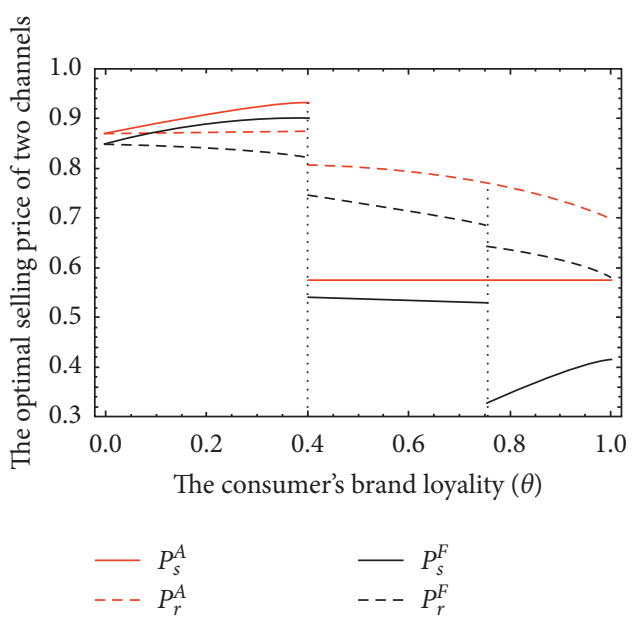

(b)

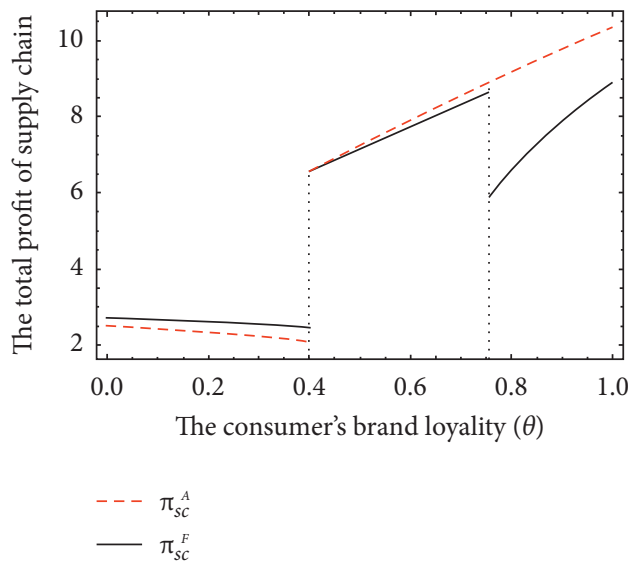

(d)

Figure 2: The impact of consumers' brand loyalty on decisions and profits. (a) The impact of $\theta$ on wholesale price. (b) The impact of $\theta$ on online price. (c) The impact of $\theta$ on participants' profits. (d) The impact of $\theta$ on total profit of supply chain.

online channel is most beneficial to the supplier, while only opening offline channel is more beneficial to the retailer. From here, we can see the important value of brand loyalty to the enterprises.

5.3. Impact of Consumers' Brand Loyalty on Decisions and Profits. Figure 2 demonstrates the impacts of consumers' brand loyalty on the optimal price decisions and profits of supply chain.

Obviously, when the other parameters remain the same, the supplier and the retailer will face three different situations as $\theta$ changes from Figure 2. (i) When consumers' brand loyalty is low, the supplier will choose only offline channel strategy. Meanwhile, the profits of all participants will decrease as $\theta$ increases if the supplier's capitals are adequate, implying that increasing retail price when consumers' brand loyalty is weak will reduce consumer purchases. However, if the supplier's capital is fully used, the supplier will lower the wholesale price, which will lead to an increase in the retailer's profit. This means that inadequate capitals from the supplier have given the retailer more power. (ii) With the increase of consumers' brand loyalty, the supplier will choose to open dual channels. We can see from Figure 2(b) that both the supplier and the retailer will cut selling prices when entering dual channels, but the benefits from supplier are enough to offset the cost of opening online channel. Therefore, it is profitable for the supplier to strive to increase consumers' brand loyalty and wait for opportunities to enter dual channels. However, the retailer's profit is much smaller than that when only offline channel is opened, especially when the supplier has adequate capitals, owing to the fact that it will not easily adjust the wholesale price. (iii) When consumers' brand loyalty is high enough, the supplier will choose only online channel strategy. It is clear that the supplier's profit will continue to increase at this time because it has an absolute brand advantage. In particular, the supplier who wants to open only online channel also needs to make certain price cuts to attract customers if its capitals are inadequate, while it can use other means such as advertising if capitals are adequate. In addition, the total profit of supply chain is higher with inadequate capitals when the offline channel is opened only, and in other cases the results are exactly the opposite as in Figure 2(d). It also reflects that 


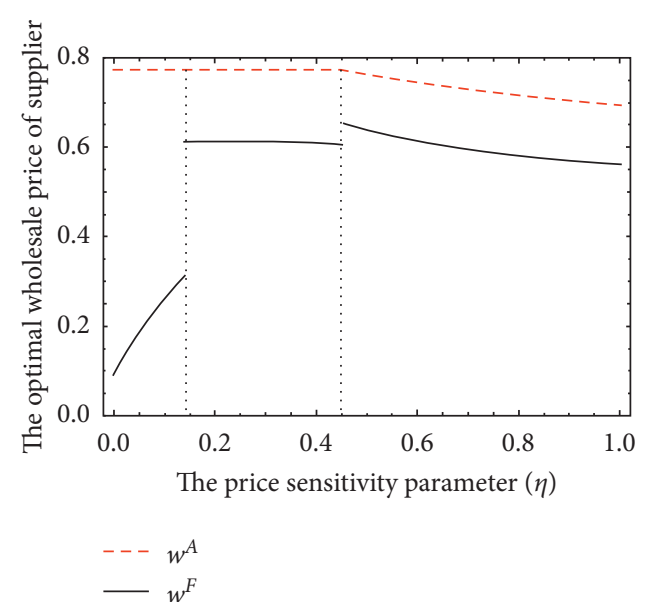

(a)

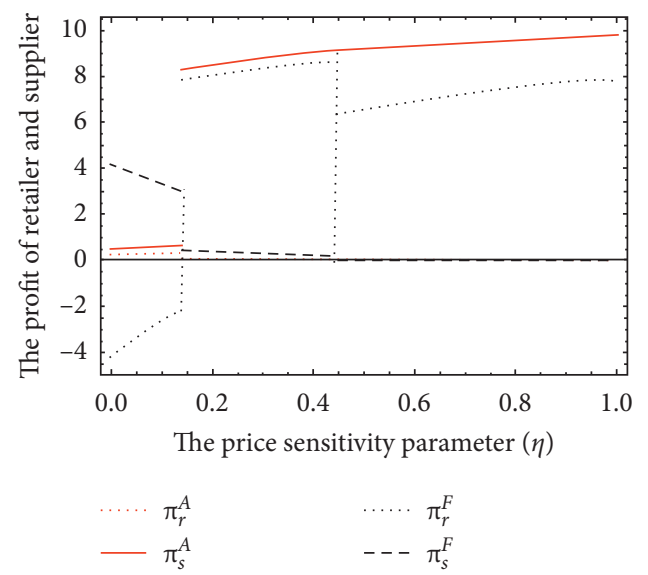

(c)

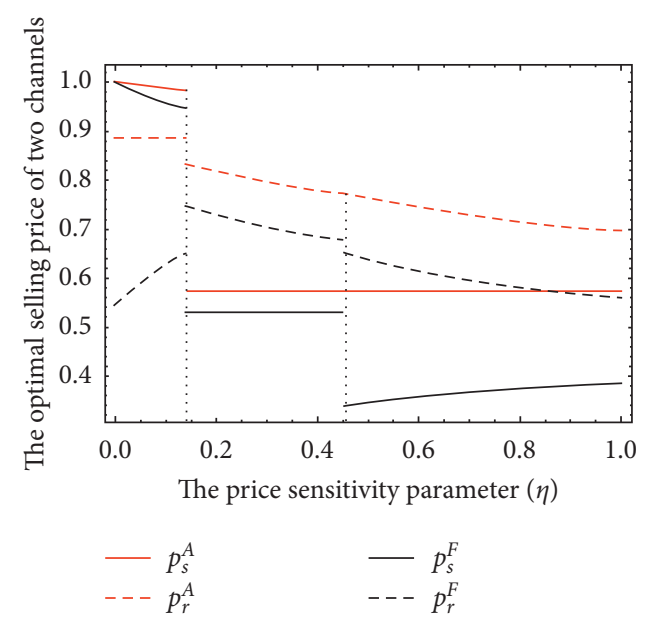

(b)

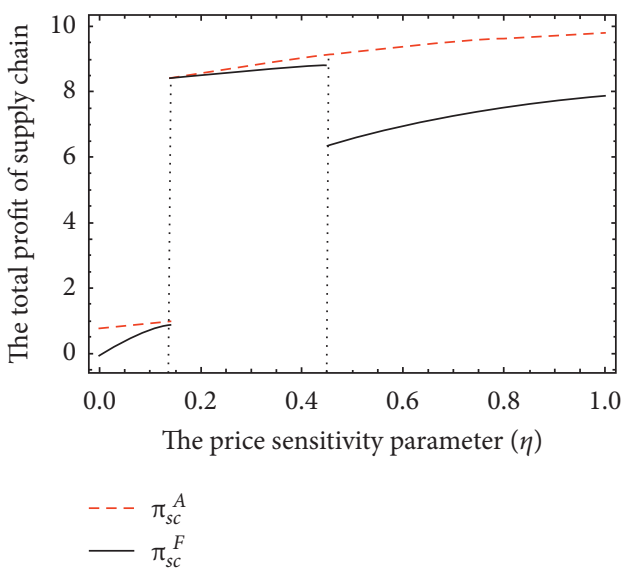

(d)

Figure 3: The impact of price-sensitivity parameter on decisions and profits. (a) The impact of $\eta$ on wholesale price. (b) The impact of $\eta$ on online price. (c) The impact of $\eta$ on participants' profits. (d) The impact of $\eta$ on total profit of supply chain.

inadequate capitals of the supplier are more beneficial to the retailer, while sufficient capitals can promote the supplier to change channel strategies to obtain greater profit.

\subsection{Impact of Price-Sensitivity Parameter on Decisions and} Profits. This subsection analyzes the influences of pricesensitivity parameter on the optimal channel strategies and profits.

It is not difficult to find from Figure 3 that, with the change of $\eta$, the supplier also faces three different channel strategies. (i) When the price sensitivity of the market is not obvious, the supplier will only open the offline channel. Moreover, neither the supplier nor the retailer will adjust the price, which will result in no significant change in their profits if the supplier's capitals are adequate. However, if the supplier's capital is inadequate, the profit of the supplier is negative, implying that the benefits from the increase in the wholesale price are not sufficient to support the capital flow, and the retailer can obtain higher profit by appropriately raising the retail price due to the price insensitivity of consumers. (ii) As the price sensitivity of the market increases, the supplier should open dual channels to implement price competition. We can find that appropriately reducing the selling price to attract customers to the online channel will bring considerable benefits to the supplier when entering the dual channels. Similarly, owing to no adjustment of wholesale price if the supplier has adequate capitals, the retailer can also achieve considerable profit by appropriately adjusting the retail price and its own loyal customers, which is a win-win situation. However, the huge increase of wholesale price will seriously damage the retailer's income if the supplier's capitals are insufficient. (iii) If the price sensitivity is too high, the supplier should only open online channel in order to avoid price wars with the retailer and maintain customers through consistently lower selling price. In addition, when the capitals are insufficient, it should try to reduce price to attract customers to online channel. Therefore, the supplier can promote price competition when consumers are sensitive to prices and maintain sufficient capital to maximize its profit, but increased price competition is not good for the retailer. 


\section{Conclusions}

With the rapid development of e-commerce, the online transactions are simple, efficient, and costly, attracting more and more suppliers to open online channel. Additionally, capital constraint is an important factor that the suppliers cannot ignore when formulating channel strategies. Therefore, if the capital constraint of the supplier is considered, this paper explores how the factors will affect the supplier's channel selection and the impacts of different strategies on the profits of the supplier and the retailer. Meanwhile, we obtain some managerial insights as follows. First, the impact of capital constraints on the supplier's channel selection and price decisions is significant. The supplier should adjust prices in a timely manner according to channel strategy when capitals are inadequate and only open online channel to obtain the highest return when capitals are adequate. Second, when the consumer's brand loyalty or market price sensitivity is low, the supplier should only open offline channel and keep the wholesale price unchanged if the capitals are adequate. Meanwhile, if capitals are inadequate, the price needs to be adjusted, implying that the retailer gains more benefits by mastering more channel resources. Finally, when a supplier first enters an online channel (whether in dual channels or an online channel only), it needs to cut prices significantly to attract customers. However, with the increase of brand loyalty or price sensitivity, the supplier can obtain rich profit without adjusting the price if capitals are adequate, but the inadequate capitals of the supplier are more favourable to retailer.

There are also some issues for future research. For example, this paper only analyzes the effect of financial constraints on decisions from the perspective of the supplier, while the situation considering both the supplier and the retailer facing financial constraints remains to be explored. Furthermore, the extension with the uncertain demand is also an interesting topic.

\section{Data Availability}

All data are included within the paper.

\section{Conflicts of Interest}

The authors declare no conflicts of interest.

\section{References}

[1] G. G. Cai, X. F. Chen and Z. G. Xiao, The roles of bank and trade credits:Theoretical analysis and empirical evidence," Production and Operations Management, vol. 23, no. 4, pp. 583-598, 2014.

[2] Y. M. Zhu, X. Witmann, and M. W. Peng, "Institution-based bariers to innovation in SMEs in China," Asia Pacific Journal of Management, vol. 29, pp. 1131-1142, 2012.

[3] S. K. Mukhopadhyay, D. Q. Yao, and X. Yue, "Information sharing of value-adding retailer in a mixed channel hi- tech supply chain," Journal of Busines Research, vol. 61, no. 9, pp. 950-958, 2008.

[4] J. T. Xu, Q. Qi, and Q. G. Bai, “Coordinating a dual-channel supply chain with price discount contracts under carbon emission capacity regulation," Applied Mathematical Modelling, vol. 56, pp. 449-468, 2018.

[5] P. Zhang, Y. He, and X. Zhao, "“Preorder-online, pickup-instore" strategy for a dual-channel retailer," Transportation Research Part E: Logistics and Transportation Review, vol. 122, pp. 27-47, 2019.

[6] X. Chen, X. J. Wang, and H. K. Chan., "Channel coordination through subsidy contract design in the mobile phone industry," International Journal of Production Economics, vol. 171, pp. 97-104, 2019.

[7] Y. He, P. Zhang, and Y. Yao, "Unidirectional transshipment policies in a dual-channel supply chain," Economic Modelling, vol. 40, pp. 259-268, 2014.

[8] M.-B. Jamali and M. Rasti-Barzoki, "A game theoretic approach for green and non-green product pricing in chain-to-chain competitive sustainable and regular dual-channel supply chains," Journal of Cleaner Production, vol. 170, pp. 1029-1043, 2018.

[9] X. H. Han, H. Y. Wu, Q. X. Yang, and J. Shang, "Reverse channel selection under remanufacturing risks: Balancing profitability and robustness," International Journal of Production Economics, vol. 182, pp. 63-72, 2016.

[10] L. Xu and C. X. Wang, "Sustainable manufacturing in a closed-loop supply chain considering emission reduction and remanufacturing," Resources, Conservation and Recycling, vol. 131, pp. 297-304, 2018.

[11] P. X. Yi, M. Huang, L. J. Guo et al., "Dual recycling channel decision in retailer oriented closed-loop supply chain for construction machinery remanufacturing," Journal of Cleaner Production, vol. 137, pp. 1393-1405, 2016.

[12] Q. H. Zhao, J. Jin, X. Q. Deng, and D. Wang, "Considering environmental implications of distribution channel choices: a comparative study based on game theory," Journal of Cleaner Production, vol. 167, pp. 1155-1164, 2017.

[13] E. Olivares-Benitez, R. Z. Rios-Mercado, and J. L. GonzalezVelarde, "A metaheuristic algorithm to solve the selection of transportation channels in supply chain design," International Journal of Production Economics, vol. 145, no. 1, pp. 161-172, 2013.

[14] J. S. Bian, X. L. Guo, and K. W. Li, "Decentralization or integration: Distribution channel selection under environmental taxation," Transportation Research Part E: Logistics and Transportation Review, vol. 113, pp. 170-193, 2018.

[15] M. Ullah and B. Sarkar, "Recovery-channel selection in a hybrid manufacturing-remanufacturing production model with RFID and product quality," International Journal of Production Economics, vol. 219, pp. 360-374, 2020.

[16] R. L. Yan and Z. X. Cao, "Product returns, asymmetric information, and firm performance," International Journal of Production Economics, vol. 185, pp. 211-222, 2017.

[17] X. Xu and J. E. Jacksonb, "Investigating the influential factors of return channel loyalty in omni-channel retailing," International Journal of Production Economics, vol. 216, pp. 118132, 2019.

[18] B. T. Chen and J. Chen, "When to introduce an online channel, and offer money back guarantees and personalized pricing?" European Journal of Operational Research, vol. 257, pp. 614-624, 2017

[19] P. He, Y. He, and H. Xu, "Channel structure and pricing in a dual-channel closed-loop supply chain with government subsidy," International Journal of Production Economics, vol. 213, pp. 108-123, 2019. 
[20] Q. H. Lu and N. Liu, "Effects of e-commerce channel entry in a two-echelon supply chain: A comparative analysis of singleand dual-channel distribution systems," International Journal of Production Economics, vol. 165, pp. 100-111, 2015.

[21] J. R. Zhang, O. Sevilay, and D. Sanchoy, "Price differentiated channel switching in a fixed period fast fashion supply chain," International Journal of Production Economics, vol. 193, pp. 31-39, 2017.

[22] P. Zhang, Y. He, and C. V. Shi, "Retailer's channel structure choice: online channel, offline channel, or dual channels?" International Journal of Production Economics, vol. 191, pp. 37-50, 2017.

[23] R. Amit and J. K. Jha, "Pricing and coordination strategies of a dual-channel supply chain considering green quality and sales effort," Journal of Cleaner Production, vol. 218, pp. 409-424, 2019.

[24] Y. He, H. Huang, and D. Li, "Inventory and pricing decisions for a dual-channel supply chain with deteriorating products," Operational Research, vol. 20, pp. 1-43, 2018.

[25] L. Xu, "Analysis for waste collection and management of closed-loop supply chain with dual-channel forward logistics," International Journal of Industrial Engineering, vol. 27, p. 1,2020 .

[26] J. Zhao, J. Wei, and M. Y. Li, "Collecting channel choice and optimal decisions on pricing and collecting in a remanufacturing supply chain," Journal of Cleaner Production, vol. 167, pp. 530-544, 2017.

[27] C. F. Li, L. P. Feng, and S. Y. Luo, "Strategic introduction of an online recycling channel in the reverse supply chain with a random demand," Journal of Cleaner Production, vol. 236, 2019.

[28] L. Yang, G. Y. Wang, and C. X. Ke, "Remanufacturing and promotion in dual-channel supply chains under cap-and-trade regulation," Journal of Cleaner Production, vol. 204, pp. 939-957, 2018.

[29] R. Zhou, Y. Liao, W. J. Shen, and S. Yang, "channel selection and fulfillment service contracts in the presence of asymmetric service information. International journal of production economics," International Journal of Production Economics, vol. 222, 2019.

[30] W. Wang, G. Li, and T. C. E. Cheng, "Channel selection in a supply chain with a multi-channel retailer: the role of channel operating costs," International Journal of Production Economics, vol. 173, pp. 54-65, 2016.

[31] N. M. Modak and P. Kelle, "Managing a dual-channel supply chain under price and delivery-time dependent stochastic demand," European Journal of Operational Research, vol. 272, no. 1, pp. 147-161, 2019.

[32] L. Xu, C. X. Wang, and J. J. Zhao, "Decision and coordination in the dual-channel supply chain considering cap-and-trade regulation," Journal of Cleaner Production, vol. 197, pp. 551561, 2018.

[33] L. J. Xia, W. Q. Hao, J. J. Qin, F. Ji, and X. Yue, "Carbon emission reduction and promotion policies considering social preferences and consumers' low-carbon awareness in the capand-trade system," Journal of Cleaner Production, vol. 195, pp. 1105-1124, 2018.

[34] S. Zhao and Q. Zhu, "Remanufacturing supply chain coordination under the stochastic remanufacturability rate and the random demand," Annals of Operations Research, vol. 257, no. 1-2, pp. 661-695, 2015.

[35] S. L. Zhao, Q. H. Zhu, and L. Cui, "A decision-making model for remanufacturers: considering both consumers' environmental preference and the government subsidy policy,"
Resources, Conservation and Recycling, vol. 128, pp. 176-186, 2018.

[36] L. Cui, K.-J. Wu, and M.-L. Tseng, "Selecting a remanufacturing quality strategy based on consumer preferences," Journal of Cleaner Production, vol. 161, pp. 1308-1316, 2017.

[37] J. J. Zhao, C. X. Wang, and L. Xu, "Decision for pricing, service, and recycling of closed-loop supply chains considering different remanufacturing roles and technology authorizations," Computers \& Industrial Engineering, vol. 132, pp. 59-73, 2019.

[38] F. X. Aguilar and R. P. Vlosky, "Consumer willingness to pay price premiums for environmentally certified wood products in the U.S," Forest Policy and Economics, vol. 9, no. 8, pp. 1100-1112, 2007.

[39] S.-C. Ma, Y. Fan, J.-F. Guo, J.-H. Xu, and J. Zhu, “Analyzing online behavior to determine Chinese consumers' preferences for electric vehicles," Journal of Cleaner Production, vol. 229, pp. 244-255, 2019.

[40] Z. Liu, T. D. Anderson, and J. M. Cruz, "Consumer environmental awareness and competition in two-stage supply chains," European Journal of Operational Research, vol. 218, pp. 602-613, 2012.

[41] J. Ji, Z. Zhang, and L. Yang, "Carbon emission reduction decisions in the retail-/dual-channel supply chain with consumers' preference," Journal of Cleaner Production, vol. 141, pp. 852-867, 2017.

[42] M. Khouja, S. Park, and G. Cai, "Channel selection and pricing in the presence of retail-captive consumers," International Journal of Production Economics, vol. 125, no. 1, pp. 84-95, 2010.

[43] Q. Ding, L. X. Dong, and P. Kouvelis, "On the integration of production and financial hedging decisions in global markets," Operations Research, vol. 55, pp. 470-489, 2007.

[44] M. Dada and Q. H. Hu, "Financing newsvendor inventory," Operations Research Letters, vol. 36, no. 5, pp. 569-573, 2016.

[45] L. Ma, W. Xue, Y. Zhao, and X. Lin, "Loss-averse inventory and borrowing decisions with constraints on working capital in fashion and textiles industry," Mathematical Problems in Engineering, vol. 2013, Article ID 657641, 1-9 pages, 2013.

[46] X. Xu and J. R. Birge, "Joint production and financing decisions: modeling and analysis," Northwestern University, Evanston, IL, USA, 2004.

[47] X. Xu and J. R. Birge, "Operational decisions, capital structure, and managerial compensation: A news vendor perspective," The Engineering Economist, vol. 53, no. 3, pp. 173-196, 2008.

[48] Y. N. Jin, S. J. Wang, and Q. Y. Hu, "Contract type and decision right of sales promotion in supply chain management with a capital constrained retailer," European Journal of Operational Research, vol. 240, pp. 415-424, 2015.

[49] X. H. Feng, I. Moon, and K. Ryu, "Supply chain coordination under budget constraint," Computers \& Industrial Engineering, vol. 88, pp. 487-500, 2015.

[50] Y. Wang and Y. Zhang, "Remanufacturer's production strategy with capital constraint and differentiated demand," Journal of Intelligent Manufacturing, vol. 28, pp. 869-882, 2017.

[51] O. B. Elias, Z. R. M. Roger, and L. V. G. V José, “A metaheuristic algorithm to solve the selection of transportation channels in supply chain design," International Journal of Production Economics, vol. 145, pp. 161-172, 2013.

[52] C. Li, K.-J. Wu, and M.-L. Tseng, "Selecting a remanufacturing quality strategy based on consumer preferences," Journal of Cleaner Production, vol. 161, pp. 1308-1316, 2017. 
[53] M. M. Nikunja and K. Peter, "Managing a dual-channel supply chain under price and delivery-time dependent stochastic demand," European Journal of Operational Research, vol. 272, no. 1, pp. 147-161, 2019.

[54] G. S. Cai, Z. G. Zhang, and M. Zhang, "Game theoretical perspectives on dual-channel supply chain competition with price discounts and pricing schemes," International Journal of Production Economics, vol. 117, no. 1, pp. 80-96, 2009.

[55] L. Xu, C. Wang, and H. Li, "Decision and coordination of lowcarbon supply chain considering technological spillover and environmental awareness," Scientific Reports, vol. 7, no. 1, 2017.

[56] L. Xu, J. Shi, and J. Chen, "Pricing and collection rate for remanufacturing industry considering capacity constraint in recycling channels," Complexity, vol. 2020, Article ID 8391252, 1-13 pages, 2020.

[57] J. Wang, Z. Zhou, and M. Z. Yu, "Pricing models in a sustainable supply chain with capacity constraint," Journal of Cleaner Production, vol. 222, pp. 57-76, 2019. 